\title{
PRESIDENT'S REPORT 2021
}

Committee changes: David Malone (MU) will have served a maximum period of 6 years as secretary at the end of 2021. Many thanks to David for his sterling service over three terms. The mantle of secretary has passed to Derek Kitson (MIC/UL) to whom we are very grateful for taking on this role. We wish him well. Since Derek joined the committee as a result of his election as secretary and since all committee members who were eligible to serve a further term were re-elected, these were the only changes to the committee this year.

IMS Bulletin: I renew the Society's appreciation of Tony O'Farrell's work as Editor of the Bulletin and to the Editorial team. The Bulletin is freely available online from the Society's homepage while attractive printed copies are available from lulu.com. In future, institutional members will receive a complimentary printed copy of each issue.

On the initiative of J.P. McCarthy (MTU), the process of arranging for the Bulletin to be indexed on SCOPUS is in train and proceeding well. In that regard, a 'publication ethics and publication malpractice statement' approved by the IMS Committee has been added to the Bulletin's webpage.

Thanks to David Malone, all articles in the Bulletin now have a DOI (Digital Object Identifier). Both the Scopus and the DOI initiatives raise the standing of the Bulletin and make publishing therein more attractive.

Eleanor Lingham (Sheffield-Hallam) is a most welcome addition to the Editorial Board as Book Reviews Editor.

IMS website and twitter feed: Michael Mackey (UCD), in addition to maintaining an up-to-date IMS website, has refreshed the site and introduced a more streamlined and modern design. Cliff Gilmore (Manchester) has taken over the Society's twitter feed, which had fallen somewhat into abeyance. In this era of social media, it is important that the Society has a robust online presence. I thank Michael and Cliff for their work in this regard.

IMS meetings: The Society's annual 'September Meeting', that was held over from 2020 due to the coronavirus pandemic, was hosted online by Brien Nolan and Niamh O'Sullivan (DCU) from 13 to 15 January 2021. The meeting, at which several of the talks focused on epidemiological and environmental modelling, was an unequivocal success.

The 2021 annual meeting was capably and smoothly organised by Cónall Kelly (UCC) and J.P. McCarthy (MTU) and jointly hosted by these two Munster universities, this in spite of the many additional complications consequent on ever changing public health guidelines. The highly successful meeting took place from 2 to 3 September in a hybrid face-to-face/online format that brought some most welcome normality into our pandemic-dominated lives.

The annual meeting in 2022 is scheduled to be held at TU Dublin, organised by Dana Mackey, Milena Venkova and Mercedes Jordan-Santana.

Thanks to all organisers and their institutions, past, present and future, for hosting the Society's annual meeting with such admirable aplomb.

IMS conference support: Due to the coronavirus pandemic, there were no applications for conference support in 2021. The Treasurer, Cónall Kelly, has issued a call for applications to support conferences taking place between January and June 2022. 
EMS Meeting of Presidents: I attended the annual European Mathematical Society (EMS) Meeting of Presidents that was held online on Saturday 29 May and on which I subsequently reported to the membership by email. Of particular note are the revamped EMS Magazine, formerly the EMS Newsletter, including its occasional Young Mathematicians Column; the 'events' and 'jobs' listings on the EMS website; the EMS publishing house, EMS Press, which has a number of journals that operate under a Subscribe to Open (S2O) model. Note also that the Zentralblatt reviewing service is now free online as zbMATH Open.

Kovalevskaya Grants and IMS Travel Grants: The Intenational Congress of Mathematicians (ICM22) will be held, under the auspices of the International Mathematical Union, in Saint Petersburg from 6 to 14 July 2022. The Local Organising Committee of ICM22, in the person of Professor Dmitry Belyaev (Oxford), contacted the IMS to ask if the Society would nominate early career researchers for 'Kovalevskaya Grants' to attend ICM22 and then support these researchers through grants covering travel to Saint Petersburg. Kovalevskaya Grants are generous, covering the registration fee and all local expenses including accommodation and meals. Grant holders will receive assistance with logistics in Saint Petersburg and visa-free entry.

The IMS sought applications for Kovalevskaya Grants, as well as accompanying IMS Travel Grants, with a closing date of 30 September. Following evaluation by the IMS Committee, 5 grants were awarded. A further 5 candidates are on a reserve list in case further Kovalevskaya Grants become available during December.

International Mathematical Union: I wrote in March, on behalf of the Society, to Minister Simon Harris T.D., Department of Further and Higher Education, Research, Innovation and Science, requesting Government endorsement of the Irish Mathematical Society to continue to act as adhering body for the IMU and, consequent on such decision, that the Government would fund Ireland's membership of the IMU in 2021 and in subsequent years. The Department of FHERIS replied to say that the correspondence had been forwarded to the Department of Education as the matter was deemed more appropriate to that department. I wrote a follow-up letter to the Department of Eduction in June which was acknowledged but otherwise no response has been received.

Ireland's membership of the International Astronomical Union (IAU) shares a similar predicament to that of the IMU. It was agreed at the IMS Committee meeting in September that the IMS and the Astronomical Society of Ireland, whose president is Dr Deirdre Coffey (UCD) and is now the Adhering Organisation for the IAU, should aim to make common cause. It was further agreed at the Committee Meeting and at the AGM that the Society would pay Ireland's IMU membership fee for 2021.

At the start of November, I wrote to Dr Jennifer Brennan, Director of Research, Development and Innovation at the Technological Higher Education Association (THEA) and Professor Jim Livesey (VP for Research and Innovation at NUIG and Chair of IUA VP/Deans of Research Standing Group) seeking the support of the research community for our campaign. Carbon copies were sent to Dr Deirdre Coffey, President of the Astronomical Society of Ireland; Professor Mark W. J. Ferguson, Director General of SFI and Chief Scientific Advisor to the Irish Government; Dr Lisa Keating, Director of Research \& Innovation, IUA; and Professor Philip Nolan, Chair of IEMAG and incoming Director General of SFI. At time of writing, no response to this correspondence has been received.

It is a priority for the Society that this matter be progressed at Government level and that the long term sustainability of Ireland's membership of the IMU be put on a firm footing.

Tom Carroll, December 2021.

E-mail address: t.carroll@ucc.ie 